\title{
Experimental analysis on small- scale finger-jointed specimens at elevated temperatures
}

\section{Journal Article}

Author(s):

Klippel, Michael; Clauss, Sebastian; Frangi, Andrea (1)

Publication date:

2014-07

Permanent link:

https://doi.org/10.3929/ethz-b-000084578

Rights / license:

In Copyright - Non-Commercial Use Permitted

Originally published in:

European Journal of Wood and Wood Products 72(4), https://doi.org/10.1007/s00107-014-0810-z 


\title{
Experimental analysis on small-scale finger-jointed specimens at elevated temperatures
}

\author{
Michael Klippel • Sebastian Clauß • \\ Andrea Frangi
}

Received: 1 May 2013/Published online: 1 June 2014

(c) Springer-Verlag Berlin Heidelberg 2014

\begin{abstract}
Finger joints have to meet strength performance requirements for the use in structural engineered wood products such as glued-laminated timber beams (glulam). Among these, the thermal stability of the adhesive used in the finger joint is an important criterion to determine the suitability of the connection. The influence of adhesives on the load-carrying capacity of glulam beams and finger-jointed members can be assessed by large-scale fire tests; however, there are obvious benefits in using small-scale specimens tested at elevated temperatures as an alternative. In Europe, there is currently no small-scale test available to test the fire performance of adhesives in structural timber members. The work presented in this paper addresses this issue and was supported by members of a European standardisation committee to develop such a small-scale test. This paper presents, as a first step, the results of a series of tensile tests on small-scale fingerjointed specimens tested at elevated temperatures. The tests were performed with different types of adhesives which are currently also tested in large-scale fire tests. In the smallscale tests here, structural adhesives showed nearly no weaknesses with increasing temperature up to $140{ }^{\circ} \mathrm{C}$. Further, MUF and PRF adhesives showed mostly wood failure even up to temperatures of $220{ }^{\circ} \mathrm{C}$. In the next step of this investigation, the results obtained from the smallscale tests at elevated temperature will be compared to
\end{abstract}

M. Klippel ( $₫) \cdot$ A. Frangi

ETH Zurich, Institute of Structural Engineering,

Wolfgang-Pauli-Strasse 15, 8093 Zurich, Switzerland

e-mail: klippel@ibk.baug.ethz.ch

S. Clauß

ETH Zurich, Institute of Building Materials, Schafmattstrasse 6,

8093 Zurich, Switzerland large-scale fire test results in order to find a possible link between both testing methods.

\section{Introduction}

Large-scale fire resistance tests on glulam beams (König et al. 2008) and finger-jointed timber boards (Klippel et al. 2013) clearly demonstrated the influence of adhesives on the load-carrying capacity of such members. However, large-scale fire tests are time intensive and expensive and can only be performed in certified fire laboratories. Further, small-scale tests can be much more enhanced leading to increasing repeatability and reproducibility, the costs can be reduced significantly, and the tests can be performed by the adhesive manufactures themselves while developing the product. Small-scale tests are usually performed at constantly elevated temperature-in case of ASTM D7247-07 (2007) up to a maximum temperature of $232{ }^{\circ} \mathrm{C}$ - and thus under a steady state, which is a different to the existing transient state in fire tests.

Building codes in different countries such as Canada and the United States as well as a guideline in Japan (NTI 2009) require large-scale fire-resistance tests to ensure that construction materials and elements meet the requirements specified in, for example, ASTM E119-05a (2006) or CAN/ULC S101-07 (2007). As an alternative to large-scale testing of each structural application, small-scale tests were developed in those countries to test the shear strength of adhesives at elevated temperatures.

The standard ASTM D7247-07 (2007) prescribes a method for performing oven tests with pre-heated specimens with lap-shear joints and applying acceptance criteria that include temperatures up to $232{ }^{\circ} \mathrm{C}$. The objective of this standard is to evaluate the adhesive performance at 
elevated temperatures near wood ignition (Yeh and Brooks 2006). The adhesive is considered acceptable if the ratio of the mean residual shear strength between the target temperatures, i.e. $21{ }^{\circ} \mathrm{C}\left(70{ }^{\circ} \mathrm{F}\right)$ and $232{ }^{\circ} \mathrm{C}\left(450{ }^{\circ} \mathrm{F}\right)$, for the bonded specimen is equal to or higher than the lower $95 \%$ confidence interval on the ratio of the mean residual shear strength for solid wood specimens. However, no link between these tests and the performance in fire has been demonstrated (König et al. 2008).

In Canada, adhesives are tested at elevated temperatures by means of a creep test according to CSA O112.9-04 (2004). This test was developed on the basis of the test method according to ASTM D3535-05 (2005). The tests are performed using a special testing device to apply a load via a large spring on the test specimen. The test specimen contains a series of 28 shear planes and is loaded to induce a stress of 2.1 MPa based on the total shear plane area. The tests are performed in an oven at $180{ }^{\circ} \mathrm{C}$ target temperature for $2 \mathrm{~h}$. To pass this test, no bonded section of a specimen is allowed to fail during the tests and maximum deformation at any shear plane should be less than $0.6 \mathrm{~mm}$. It is worth noting that Craft et al. (2008) found that the testing temperature should be increased to $220{ }^{\circ} \mathrm{C}$ since adhesives fulfilling the tests at $180{ }^{\circ} \mathrm{C}$ failed in large-scale fire tests.

A new test method was recently developed at FPInnovations (formerly Forintek), Canada, to test finger-jointed specimens at elevated temperatures applying a tensile load, since it might be more appropriate than lap-shear tests for applications where finger joints are loaded under pure tension (Craft et al. 2008). In North-America as well as in Scandinavian countries this method could be applied to finger joints in the bottom flange of an I-joist. Further, for glulam beams, for which the beam depth is much greater than the thickness of the single laminations, the bottom or top outer finger-jointed lamination is subjected to almost pure tension. The method of FPInnovations combines the ASTM D4688-99 (2005) and the CSA O112.9-04 (2004) standards. A small finger-jointed specimen is tested in a tensile creep test at $220{ }^{\circ} \mathrm{C}$. The initial target stress in the cross-section is $10.3 \mathrm{MPa}$. The time to failure is measured, and the effect of loading as well as the effect of heating under load is investigated (Craft et al. 2008). It was found that the testing temperature of $220{ }^{\circ} \mathrm{C}$ is not too high since phenol-resorcinol-formaldehyde resin (PRF) and melamine-formaldehyde resin (MF) adhesives fulfilled the requirements of the tests. The studied polyurethane (PUR) and poly(vinyl acetate) (PVA) samples failed in these investigations, reaching only a low failure time and little or no wood failure could be observed. However, this test procedure might capture long-time heating of structural timber members rather than represent an appropriate method to investigate the short, intensive temperature influence as it occurs in some fire situations.
A series of tensile tests on finger-jointed specimens meant for the use in glulam beams has been carried out by Nielsen and Olesen (1982). They aimed to analyse the influence of temperature on the timber strength of finger joints parallel-to-grain. Therefore, they performed tests at elevated temperatures and found that the tensile strength of unjointed boards was higher than the tensile strength of finger joints tested at a temperature of $90{ }^{\circ} \mathrm{C}$. More recently, Frangi et al. (2012) conducted a series of tensile tests at elevated temperatures with finger joints bonded with five different adhesives [four different one-component polyurethane (1C PUR) adhesives and one melamine-ureaformaldehyde (MUF) adhesive]. The tests showed a significant temperature-dependent reduction in strength for the finger joints tested. Further, substantial differences in strength reduction and failure were observed between the different adhesives tested. The relative strength reduction, e.g. at $100{ }^{\circ} \mathrm{C}$ varied between 50 and $85 \%$ of the strength at normal temperature $\left(20^{\circ} \mathrm{C}\right)$. Specimens bonded with three different adhesives showed a strength reduction greater than the expected strength reduction of timber in fire.

Another study investigating the shear behaviour of different adhesives at elevated temperatures was carried out by Frangi et al. (2004). The results demonstrated that the behaviour of PUR adhesives strongly depends on the chemical composition of the adhesive. Further investigation by Clauß et al. (2011b) on the influence of temperature on the shear strength of glued wood joints showed large differences in thermal resistance and fracture behaviour between the adhesive systems tested. The thermal behaviour of 1C PUR systems can be varied greatly by modifying their chemical structure (Clauß et al. 2011b). Test results based on one particular PUR adhesive are, therefore, not valid for other PUR adhesives. The use of filler materials for example can significantly influence the adhesive performance under thermal load (Clauß et al. 2012).

The creep behaviour of adhesive bonds at elevated temperature was investigated by George et al. (2003) and $\mathrm{Na}$ et al. (2005). In these investigations, a temperaturedependant creep of PUR adhesives was found between 40 and $80{ }^{\circ} \mathrm{C}$. Furthermore, a higher initial strength (caused by a higher content of isocyanate) led to a reduction of the creep in the low temperature range up to $50^{\circ} \mathrm{C}$. The relationship between the chemical structure and temperature-dependent creep properties of different commercial PURs was investigated by Richter et al. (2006). Comparing the mechanical performance of the adhesive by means of ${ }^{13} \mathrm{C}-\mathrm{NMR}$ spectroscopy (Carbon-13 nuclear magnetic resonance spectroscopy), they found that the combination of a few chemical parameters had a big impact on the thermal stability of 1C PUR adhesives. These parameters were the 
relative proportion of remaining-NCO groups in the PURs, the degree of polymerisation of the prepolymer and also the rate of reaction.

In Europe, structural adhesives must comply with performance requirements given in EN 301 (2013), EN 15425 (2008) and prEN 16254 (2013). With regard to performance at elevated temperature, the highest temperature in the tests according to these standards is $90{ }^{\circ} \mathrm{C}$, being held over 2 weeks under constant loading of the specimens (EN 15416-2 2013). Therefore, the current European standards might not provide sufficient information, nor do they give a classification for adhesives at elevated temperature appropriate for fire design.

In 2009, a standardisation committee (CEN TC 193/SC1/WG13) was formed in Europe to address the adhesive performance at elevated temperatures and in fire situations. The development of an appropriate testing method to test adhesives used in structural timber elements and exposed to fire should involve large-scale fire tests. A direct link between the performance of adhesives in a small-scale test method at elevated temperatures and large-scale fire tests should be established, if possible. This approach was found to be relevant, since adhesives should not be excluded from the market on the basis of small-scale tests although they exhibit sufficient strength in real fire tests. Further, the development of appropriate small-scale testing methods should consider the following requirements:

- The preparation of the specimens should be easy.

- The test should create reproducible results.

- The test should be performed at elevated temperatures; however, the performance of the adhesives used in engineered wood products exposed to fire should be reflected in an adequate temperature exposure. Thereby, the testing temperature might depend on the adhesive application in different timber components.

In engineered wood products, such as glulam beams, a steep temperature gradient occurs when they are exposed to fire (e.g. Mikkola 1990). This steep temperature gradient leads to relatively low temperatures in the inner part of the cross-section after a time of fire exposure the timber member was designed for. This fact implicates that appropriate testing methods to capture the fire performance of adhesives in glulam should not test adhesives at temperatures above $220{ }^{\circ} \mathrm{C}$, as it is done in ASTM D7247-07 (2007). The adhesive used in e.g. glulam needs sufficient thermal strength at much lower temperatures in a fire situation, which was shown by Klippel et al. (2013).

In the framework of a comprehensive research project currently performed at ETH Zurich, different commercially available adhesives have been investigated both in large-scale fire tests as well as in small-scale tests at elevated temperatures. This paper presents the investigations on finger-jointed small-scale specimens at elevated temperatures. The investigation was supported by the members of the European standardisation committee CEN TC 193/SC1/WG13 being one possibility to perform small-scale tests at elevated temperatures for the evaluation of the adhesive performance in fire. The whole investigation states to be the first comprehensive research on the performance of adhesives both in small-scale tests at elevated temperatures and large-scale fire tests. The chosen adhesives are currently used in the wood industry in structural timber members and are thus certified according to current European testing standards. Further, adhesives were tested which are not certified for the use in structural timber members in order to determine the difference to adhesives used in structural timber members with respect to their thermal stability. In total, about 570 tests were performed with 12 different adhesives by means of tensile tests on finger-jointed specimens at temperatures between 20 and $220{ }^{\circ} \mathrm{C}$. The same adhesives are currently being tested in large-scale fire tests in fingerjointed timber members of structural size. A possible link between both test methods should be established in the next steps.

The investigation concentrates on the behaviour of adhesives in finger joints since this connection was found to possibly have an influence on the load-carrying resistance of glulam beams in fire (König et al. 2008; Klippel et al. 2011). The results presented in this paper establish the first step to provide a comprehensive background for the introduction of appropriate acceptance criteria for adhesives used in engineered wood products in Europe.

\section{Materials and methods}

\subsection{Wood}

The finger-jointed specimens were cut out from industrially produced large-scale lamellas from Norwegian spruce (Picea abies). The boards were selected complying with strength class C30 in accordance with EN 338 (2009). Further, the ends of the original boards were cut at preselected areas to ensure that no knots appeared in the fingerjointed region of the lamella. In order to obtain a reference value for the tensile strength, specimens without finger joints were also produced. Before testing, the specimens were preconditioned in a climate chamber $\left(20{ }^{\circ} \mathrm{C} / 65 \%\right.$ RH). The raw density $\rho$ at an EMC $\omega$ of $12 \pm 1 \%$ was measured for both boards of each finger-jointed specimen and amounted to an average value of $412 \mathrm{~kg} / \mathrm{m}^{3}$. This value is the average of the lower density of both boards connected with the finger joint. 


\subsection{Adhesives}

Commercially available adhesives from different producers in Europe were investigated in this study with regard to their thermal stability. Adhesives used in structural timber members in Europe must fulfil the requirements of EN 301 (2013), EN 15425 (2008) and prEN 16254 (2013). Different systems that fulfil current approval criteria according to these standards were tested as follows (given is the full name and the abbreviation in the present study):

- Emulsion-polymer-isocyanate (EPI)

- One-component polyurethane (1C PUR: P2, P3, P4, P6)

- Melamine-urea-formaldehyde resin (MUF: M1, M2)

- Phenol-resorcinol-formaldehyde resin

These adhesives fulfil at least the requirements at a maximum temperature of $70{ }^{\circ} \mathrm{C}$ according to EN 302-1 (2013). In addition to the adhesives used in structural members, adhesives were also tested which are not certified according to European standards for the use in structural timber members:

- Urea-formaldehyde resin (UF)

- Melamine-urea-formaldehyde resin (MUF: M3)

- Poly(vinyl acetate) (PVAc)

- One-component polyurethane (1C PUR: P7)

\subsection{Production of the specimens}

All specimens were prepared by the same certified manufacturer of glulam beams in Switzerland under the supervision of the adhesive manufacturers. Finger-jointed specimens were produced with a cross-section dimension of $40 \times 140 \mathrm{~mm}^{2}$. In the next step, from each board twelve small-scale specimens were cut out with a cross-section of about $5 \times 40 \mathrm{~mm}^{2}$. Finally, the cross-section in the fingerjointed region was reduced to achieve failure in this region using a milling machine. The specimen and its dimensions are shown in Fig. 1.

\subsection{Testing procedure and program}

To investigate the influence of the temperature on the tensile strength, the specimens were first pre-heated in a drying chamber for $1 \mathrm{~h}$ at the target temperatures of 90 , 110,140 or $220{ }^{\circ} \mathrm{C}$, respectively. The tensile tests were performed in a climate chamber at the exact target temperature, which is a big advantage of this test series. The temperature was recorded by a thermocouple fitted in some dummy specimens by drilling a small hole to mid-depth and secured using epoxy. Since the test specimen is relatively thin, the temperature in the middle of the specimen does not take a long time to equilibrate after the pre-

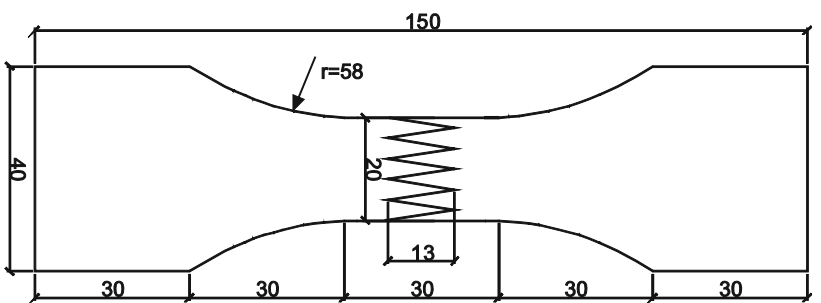

Fig. 1 Dimensions of test specimens in $\mathrm{mm}$ (depth: $5 \mathrm{~mm}$ )

heating and putting in the testing machine. The recovery time of the oven temperature after the door is opened and subsequently closed depends upon the target temperature and took on average about $5 \mathrm{~min}$. After the pre-heating period and before putting the specimen in the testing machine, the cross-section in the finger-jointed region and for some specimens additionally the weight was measured.

The test was performed position-controlled with a speed of $0.8 \mathrm{~mm} / \mathrm{min}$ using a universal testing machine (Zwick 1484). From initially loading to failure it took about $60 \mathrm{~s}$, which complies with the requirements according to EN 302-1 (2013). After reaching the maximum strength of the specimen, the crack pattern was investigated. For each adhesive and temperature studied, about ten specimens were tested. No tests were performed with PVAc at $220{ }^{\circ} \mathrm{C}$, since the loss in strength was already considerable at temperatures lower than $140{ }^{\circ} \mathrm{C}$. In total, 570 tests were performed.

After testing, the samples were completely dried in an oven. With the weight before and after drying, the moisture content of the specimens before the tests was determined. Additionally, the density of each finger-jointed specimen was measured from both parts of the joint. Furthermore, non-glued solid wood specimens were also tested to obtain a reference value for the tensile strength.

\section{Results and discussion}

In the tests on finger-jointed specimens, basically three different failure types were observed:

- Failure in the finger joint (Fig. 2a)

- Tensile failure of timber outside the finger joint (Fig. 2b)

- Mixed-type failure (Fig. 2c)

In the case of a mixed-type failure, it was not possible to determine the cause of the failure during the tests. The specimen assembly was chosen to investigate failure in the finger-jointed region; however, in some tests also failure in the area of the supports occurred. For the tests in which failure did not occur in the finger-jointed region, it can be said that the strength is at least as high as the value 

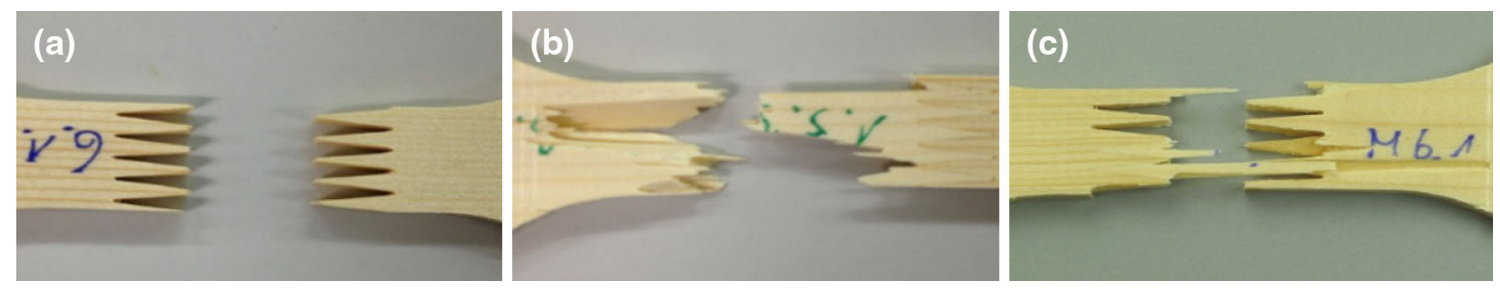

Fig. 2 Failure types observed during the tensile tests, with failure in the finger joint (a), tensile failure of timber outside the finger joint (b) and mixed-type failure (c)

Table 1 Main statistical data (mean value $\overline{\mathrm{x}}$ and coefficient of variation $v$ ) of the tensile strength for all tests performed

\begin{tabular}{|c|c|c|c|c|c|c|c|c|c|c|c|c|c|}
\hline \multirow[t]{2}{*}{$\mathrm{T}\left({ }^{\circ} \mathrm{C}\right)$} & \multicolumn{13}{|c|}{$\sigma(\mathrm{MPa})$ and $\rho_{\text {mean }}\left(\mathrm{g} / \mathrm{cm}^{3}\right)$} \\
\hline & EPI & M1 & M2 & $\mathrm{M}^{\mathrm{a}}$ & $\mathrm{P} 2$ & P3 & $\mathrm{P} 4$ & P6 & $\mathrm{P} 7^{\mathrm{a}}$ & PRF & PVAc $^{a}$ & $\mathrm{UF}^{\mathrm{a}}$ & Solid wood \\
\hline \multicolumn{14}{|l|}{20} \\
\hline$\overline{\mathbf{x}}$ & 60.70 & 55.36 & 60.29 & 62.17 & 62.24 & 61.00 & 53.86 & 45.06 & 60.57 & 55.00 & 62.64 & 59.83 & 71.50 \\
\hline$v$ & 15.46 & 12.08 & 18.05 & 15.62 & 15.19 & 12.28 & 24.06 & 28.31 & 16.26 & 13.91 & 23.40 & 12.62 & 26.18 \\
\hline$\rho_{\text {mean }}$ & 0.415 & 0.413 & 0.427 & 0.423 & 0.425 & 0.419 & 0.415 & 0.371 & 0.397 & 0.415 & 0.416 & 0.410 & 0.419 \\
\hline \multicolumn{14}{|l|}{90} \\
\hline$\overline{\mathbf{x}}$ & 46.80 & 45.40 & 44.63 & 52.68 & 52.16 & 45.37 & 44.58 & 38.89 & 44.29 & 51.05 & 12.15 & 48.24 & 63.33 \\
\hline$v$ & 12.48 & 27.26 & 27.23 & 18.30 & 19.24 & 21.04 & 17.45 & 12.80 & 15.22 & 21.11 & 64.47 & 20.57 & 24.58 \\
\hline$\rho_{\text {mean }}$ & 0.406 & 0.413 & 0.416 & 0.446 & 0.419 & 0.421 & 0.405 & 0.367 & 0.389 & 0.409 & 0.409 & 0.414 & 0.416 \\
\hline \multicolumn{14}{|l|}{110} \\
\hline$\overline{\mathbf{x}}$ & 39.82 & 39.23 & 44.20 & 48.37 & 41.85 & 43.82 & 34.79 & 34.44 & 40.48 & 50.83 & 8.85 & 43.93 & 58.33 \\
\hline$v$ & 28.14 & 18.56 & 27.23 & 12.28 & 22.96 & 15.62 & 19.60 & 15.53 & 24.75 & 18.60 & 54.37 & 15.31 & 8.75 \\
\hline$\rho_{\text {mean }}$ & 0.429 & 0.412 & 0.412 & 0.441 & 0.413 & 0.411 & 0.402 & 0.364 & 0.389 & 0.409 & 0.409 & 0.414 & 0.416 \\
\hline \multicolumn{14}{|l|}{140} \\
\hline$\overline{\mathbf{x}}$ & 31.40 & 37.98 & 41.07 & 41.69 & 40.06 & 39.00 & 32.49 & 24.20 & 34.22 & 41.83 & 9.99 & 41.59 & 49.83 \\
\hline$v$ & 5.23 & 19.61 & 19.59 & 7.12 & 26.76 & 8.53 & 16.49 & 28.16 & 9.49 & 20.63 & 30.96 & 12.04 & 36.68 \\
\hline$\rho_{\text {mean }}$ & 0.424 & 0.412 & 0.412 & 0.441 & 0.413 & 0.422 & 0.402 & 0.378 & 0.420 & 0.404 & 0.420 & 0.417 & 0.413 \\
\hline \multicolumn{14}{|l|}{220} \\
\hline$\overline{\mathbf{x}}$ & 2.51 & 19.54 & 20.74 & 23.38 & 4.03 & 17.14 & 3.14 & 2.73 & 5.74 & 20.58 & - & 7.09 & 34.32 \\
\hline$v$ & 12.39 & 32.66 & 21.70 & 11.97 & 18.49 & 29.85 & 8.66 & 17.89 & 3.46 & 32.95 & - & 30.86 & 35.40 \\
\hline$\rho_{\text {mean }}$ & 0.403 & 0.434 & 0.375 & 0.427 & 0.408 & 0.424 & 0.401 & 0.391 & 0.419 & 0.401 & - & 0.417 & 0.412 \\
\hline
\end{tabular}

In addition, the mean density of the boards with the smaller density is given

Mean values of tensile strength $\overline{\mathbf{x}}$ in (MPa), coefficient of variation $v(-)$; density $\rho_{\text {mean }}$ in $\left(\mathrm{g} / \mathrm{cm}^{3}\right)$

${ }^{a}$ Non-certified adhesive according to current European standards

determined. When failure occurred in the supporting area, the results were not taken into consideration in the further evaluation. Failure in the finger joint was further analysed in more detail by taking into account the difference between wood failure and adhesive failure (i.e. failure of the adhesion between adhesive and timber). Hence, it was basically distinguished between failure along the fingers and failure of the fingers due to exceeding the tensile strength of wood.

The tensile strength $f_{t}$ was calculated based on the crosssectional area according to the following equation:

$f_{t}=\frac{F_{u}}{A}$ with $F_{u}$ failure load, $A$ cross-sectional area $(A=5 \times 20=$ $100 \mathrm{~mm}^{2}$ ).

Table 1 summarises the main statistical data (mean value $\overline{\mathrm{x}}$ and coefficient of variation $v$ ) of all tensile tests including the reference tests performed without finger joints. For the finger joints, the tensile strength measured at normal temperature varied between 54 and $62 \mathrm{MPa}$, i.e. between 75 and $87 \%$ of the tensile strength measured from the reference specimens without finger joints, excluding the values obtained with adhesive P6. In the tests with adhesive P6, a noticeably low mean tensile strength was observed (see Table 1). The lower tensile strength for these specimens can be explained by the low density of the specimens. 
Table 2 Wood failure percentage of finger joints at different temperatures

\begin{tabular}{|c|c|c|c|c|c|c|c|c|c|c|c|c|}
\hline \multirow[t]{2}{*}{$\mathrm{T}\left({ }^{\circ} \mathrm{C}\right)$} & \multicolumn{12}{|c|}{ Wood failure $(\%)$} \\
\hline & EPI & M1 & M2 & M3 & $\mathrm{P} 2$ & $\mathrm{P} 3$ & $\mathrm{P} 4$ & P6 & $\mathrm{P} 7$ & PRF & PVAc & UF \\
\hline 20 & 100 & 100 & 100 & 100 & 100 & 100 & 100 & 100 & 100 & 100 & 100 & 100 \\
\hline 90 & 60 & 90 & 90 & 90 & 90 & 70 & 60 & 70 & 50 & 100 & 20 & 90 \\
\hline 110 & 50 & 100 & 100 & 100 & 80 & 60 & 80 & 60 & 60 & 80 & 0 & 100 \\
\hline 140 & 40 & 90 & 90 & 90 & 70 & 30 & 40 & 60 & 50 & 90 & 0 & 90 \\
\hline 220 & 0 & 100 & 100 & 80 & 0 & 10 & 0 & 0 & 0 & 100 & - & 0 \\
\hline
\end{tabular}

It is worth noticing that a low coefficient of variation in Table 1 indicates an influence of the adhesive on the structural performance of the finger joints.

At normal temperature, wood failure was observed in all tests, hence, only the timber strength was tested and the adhesive had no influence on the tensile strength. For the PVAc adhesive, a drop of the tensile strength together with a low coefficient of variation was observed already at a temperature of $90{ }^{\circ} \mathrm{C}$, as expected. A mean wood failure percentage of $20 \%$ indicates that the adhesive had already at this temperature a strong influence on the tensile strength. In Table 2, it can be seen that for the tested PUR adhesives a wood failure percentage of $0 \%$ was observed at $220{ }^{\circ} \mathrm{C}$, except for PUR adhesive P3. This type of adhesive was especially developed to fulfil the requirements of ASTM D7247-07 (2007). For the PRF and MUF systems tested in this investigation, still at $220{ }^{\circ} \mathrm{C}$ a wood failure percentage of almost $100 \%$ was observed, thus mostly the timber limited the tensile strength of the fingerjointed specimen. It is interesting to note that finger-jointed specimens of structural size glued with these PRF and MUF adhesives might not reach higher fire resistance in large-scale fire tests than finger joints produced with PUR adhesives because the tensile strength of timber governs the load-bearing resistance of the connection which has already been shown in large-scale fire tests on fingerjointed timber members by Klippel et al. (2013) on selected adhesives (M1, P2, P3, P4).

In the present study, highly cross-linked systems like PRF or MUF show clear advantages in this test but also PUR adhesives with increased cross-link density and higher amount of urea hard segments are able to resist the high temperature load as shown by Clauß et al. (2011a). However, improving the thermal stability of a system goes along with a reduction in the systems' ductility (Clauß et al. 2012). Thus, it is important to find a good balance between a sufficient thermal stability and a certain ductility of the system.

Changes in temperature are accompanied by changes in wood moisture. Above $110{ }^{\circ} \mathrm{C}$, the wood moisture of the specimens dropped to $0 \%$ (Table 3 ). A constant strength development was observed from 110 to $140{ }^{\circ} \mathrm{C}$ for some adhesives, which might be explained by the reduction in moisture. The reduction in moisture has a bigger effect on the strength than the increase of the temperature (Gerhards 1982; Glos and Henrici 1990). The results, therefore, show an interaction of both effects.

The tensile strength for all specimens depending on the adhesive in the finger joint as well as the results obtained from the solid wood specimens for the different temperatures is shown in Figs. 3, 4, 5, 6, 7. The boxplots show the quartiles of distribution with whiskers at most $1.5 \times$ interquartile range and points as outliers. The following remarks can be drawn:

- The highest variability in the results was obtained for the solid wood specimens.

- The influence of the temperature on the strength reduction can be clearly recognised.

- With increasing temperature, the variation of the results decreases since the influence of the adhesive on the tensile strength increases.

Since the density of the timber material influences the strength and stiffness of the specimen, EN 338 (2009) and EN 1194 (1999) give relationships to calculate strength and stiffness properties for different strength classes depending on the density for solid timber and for glulam of structural size, respectively. A large scatter is usually observed for the relationship between strength and stiffness depending on the density because of the natural grown material timber. However, the density is still accepted as an indicator to estimate the strength of a timber specimen.

In the present investigation, the density of each specimen tested at different target temperatures was determined. Figure 8 shows the tensile strength measured for all specimens for the different target temperatures studied vs. the density of the specimens. In the diagram, the smaller density of both boards connected with the finger joint is used, since it has been shown that the board with the lower density most likely governs the load-carrying capacity of the finger joint (Colling 1990). The influence of the temperature on the strength reduction can clearly be recognised. Further, a significant increase in the tensile strength with increasing density of the specimens tested at normal 
Table 3 Wood moisture content (mean values) of specimens before testing at different temperatures

\begin{tabular}{llllll}
\hline $\mathrm{T}\left({ }^{\circ} \mathrm{C}\right)$ & 20 & 90 & 110 & 140 & 220 \\
Wood moisture (\%) & 11.75 & 2.10 & 0.45 & 0.00 & 0.00 \\
\hline
\end{tabular}

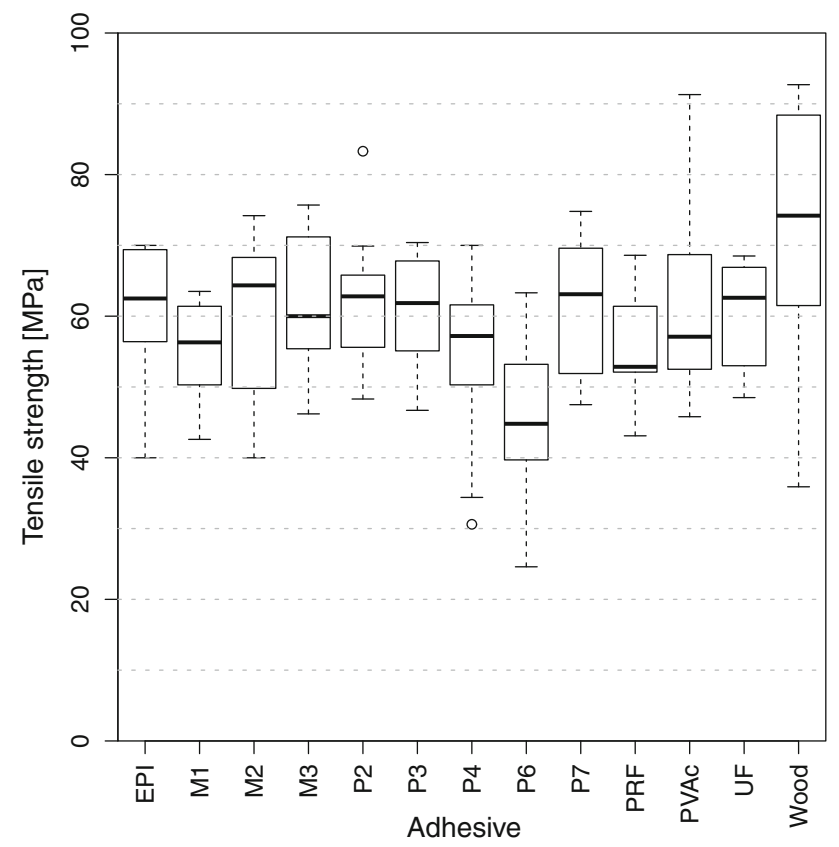

Fig. 3 Tensile strength at $20^{\circ} \mathrm{C}$

temperature was observed. It can be seen that the slope of the different lines decreases with increasing temperature. This means that the influence of the density on the tensile strength decreases with increasing temperature. At the same time, the amount of wood failure percentage decreases with increasing temperature. This fact could be expected, since at lower temperatures the performance of wood is first and foremost reflected.

Figures 9 and 10 show the tensile strength and the relative tensile strength, respectively, as a function of temperature for all studied adhesives as well as for the reference tests without finger joints. It can be seen that for the solid wood specimens the highest tensile strength was obtained for all temperature levels. For temperatures lower than $140{ }^{\circ} \mathrm{C}$, all adhesive joints showed no significant decrease in relative strength. The tensile strength at $140{ }^{\circ} \mathrm{C}$ reached on average a value of between 52 and $70 \%$ of the tensile strength at $20^{\circ} \mathrm{C}$, except for the PVAc adhesive that lost strength, as expected, at temperatures lower than $90{ }^{\circ} \mathrm{C}$.

At $220{ }^{\circ} \mathrm{C}$ a clear separation in tensile strength was observed. The adhesives can be divided into two groups with regard to the tensile strength obtained at $220^{\circ} \mathrm{C}$. The first group contains the MUF adhesives, PRF and one PUR adhesive P3, which was especially developed to reach high thermal stability. In the second group with lower tensile strength at $220{ }^{\circ} \mathrm{C}$, the EPI, UF, and the other PUR systems can be found. However, it is very important to note that this separation does not lead to the conclusion that the adhesives belonging to the second group with lower tensile strength at $220^{\circ} \mathrm{C}$ do not have sufficient strength while using them in structural members such as glulam, as demonstrated by Klippel et al. (2013).

It has previously been shown that adhesives need sufficient strength at temperatures lower than $140{ }^{\circ} \mathrm{C}$ when using them in a structural member such as glulam (Klippel et al. 2013). In Figs. 9 and 10 it can be seen that no separation in terms of tensile strength of the adhesives was observed in this investigation for temperatures lower than $140{ }^{\circ} \mathrm{C}$. Even the adhesives not certified according to the current European standards for structural applications reached similar tensile strengths to the certified adhesives, excluding PVAc. Finger-jointed specimens glued with not certified adhesives such as UF and PUR adhesive P7 still reached similar strengths for temperatures up to $140{ }^{\circ} \mathrm{C}$. As in the investigations performed by Clauß et al. (2011a), the UF adhesive showed a high thermal stability similar to MUF adhesives up to temperatures of $140{ }^{\circ} \mathrm{C}$. The UF adhesive failed completely at $220^{\circ} \mathrm{C}$. It can be concluded that the high thermal stability might not be the only influencing factor for the fire resistance of adhesives in structural timber members.

In order to establish a sound testing method to test the performance of adhesives used in structural members, it is interesting to compare different test methods with each other. The results obtained from the present investigation on small-scale tests at elevated temperatures were compared to (1) results obtained from elevated temperature tests using structural size members and (2) large-scale fire tests. Elevated temperature tests were performed by Frangi et al. (2012) on finger-jointed structural size members (cross-section $40 \times 140 \mathrm{~mm}^{2}$ ) also glued with the adhesives P2, P3, P4, M1, and solid wood specimens The following observations can be summarised comparing the results obtained from tests at elevated temperatures using small-scale specimens as presented in this paper and structural size specimens by Frangi et al. (2012):

- Figure 10 shows that the tensile strength of specimens glued with PUR adhesive P2 does not further decrease between 110 and $140{ }^{\circ} \mathrm{C}$, as observed for most other adhesives investigated. This is in accordance with the tests by Frangi et al. (2012) on structural size members. The performance of the tested adhesives depends on their chemical structure and modifications in e.g. hard segment content, cross-link density and additional filler materials that make it possible to extend the 


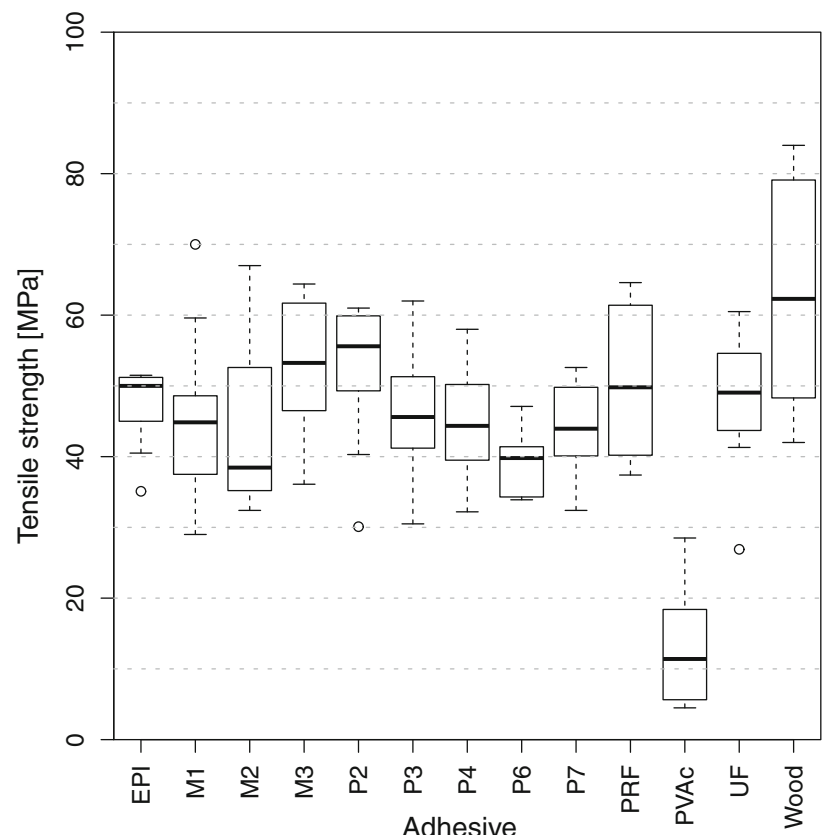

Fig. 4 Tensile strength at $90{ }^{\circ} \mathrm{C}$

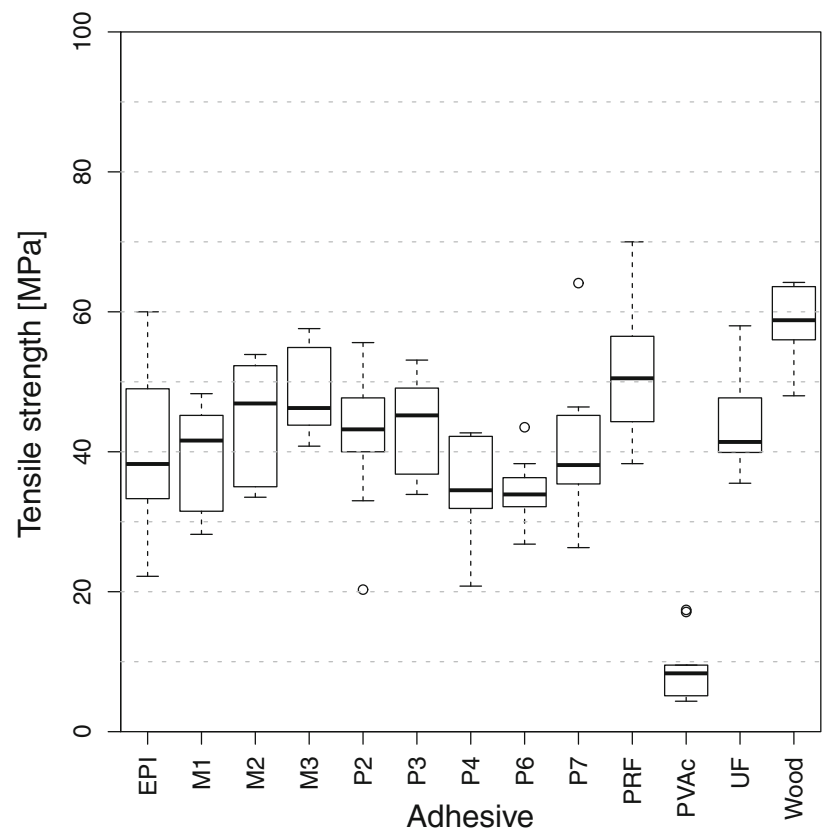

Fig. 5 Tensile strength at $110{ }^{\circ} \mathrm{C}$

temperature range to overcome a certain stress level. For the PUR adhesives P3 and P4 as well as the MUF adhesive M1, a slight decrease of tensile strength between 110 and $140{ }^{\circ} \mathrm{C}$ was found in both investigations.

- Depending on the adhesive and the temperature, the tensile strength in the present small-scale tests was 1.35-2.31 times higher than the tensile strength of the structural size members tested by Frangi et al. (2012).

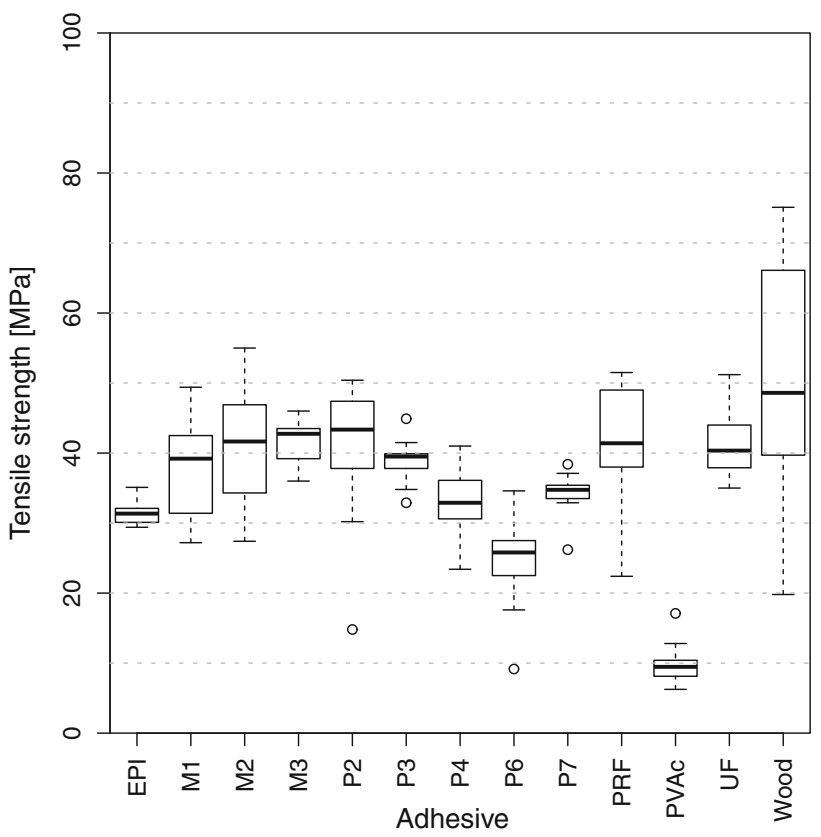

Fig. 6 Tensile strength at $140{ }^{\circ} \mathrm{C}$

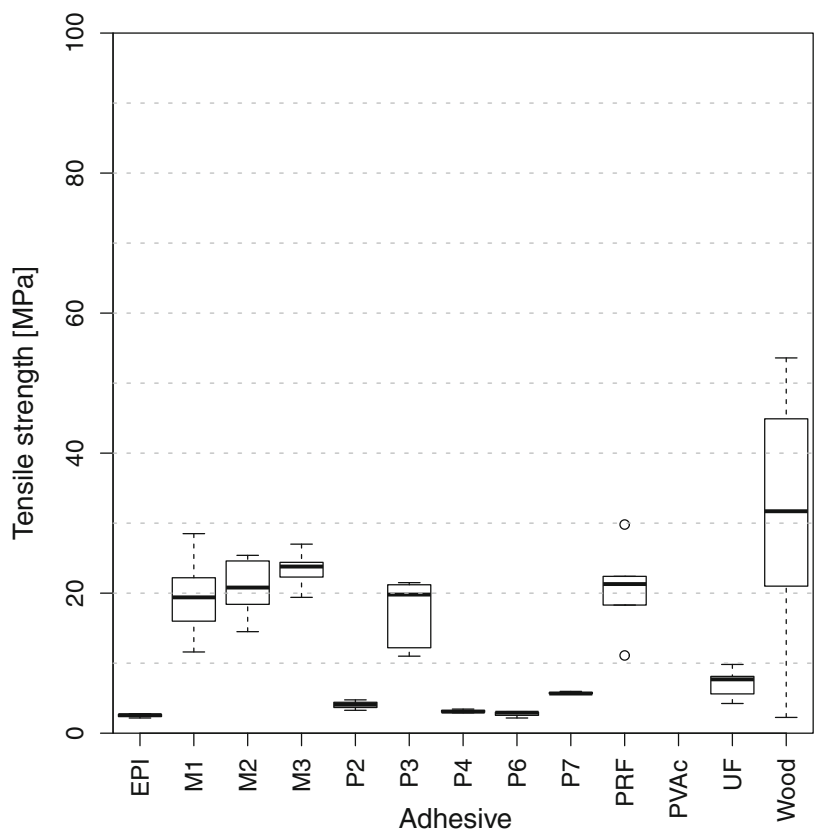

Fig. 7 Tensile strength at $220{ }^{\circ} \mathrm{C}$

- The decrease in strength at $140{ }^{\circ} \mathrm{C}$ related to the strength at normal temperature $\left(20^{\circ} \mathrm{C}\right)$, and thus the ratio of $f_{t, 140}{ }^{\circ} \mathrm{C} / f_{t, 20}{ }^{\circ} \mathrm{C}$, is similar for the PUR adhesives P2 and P4 in both testing methods. For adhesive P3 and M1, the decrease in strength is higher in the tests with structural size members than in the small-scale tests.

- The PUR adhesive P3 is approved according to ASTM D7247-07 (2007) at a temperature above $200{ }^{\circ} \mathrm{C}$. However, at $140{ }^{\circ} \mathrm{C}$ no significant difference 


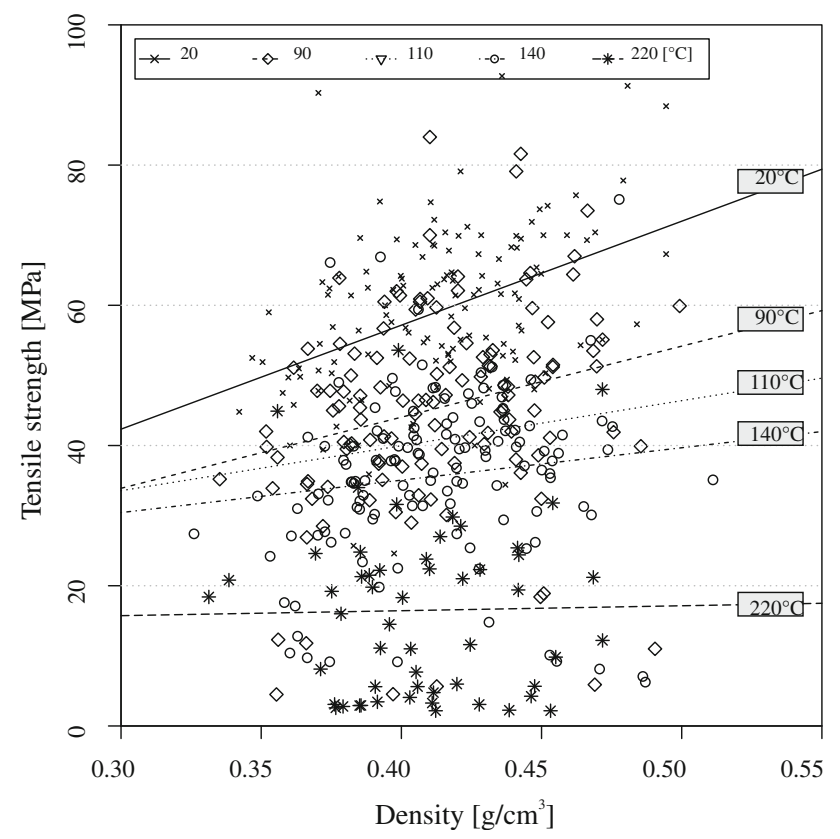

Fig. 8 Tensile strength for all specimens at different target temperatures as a function of specimens' density. Solid lines represent the results from a linear regression analysis

between the PUR adhesives P2 and P3 was observed in small-scale tests and tests on structural size members, although adhesive P2 does not pass the mentioned ASTM test.

Large-scale fire tests on finger-jointed specimens using ISO-fire (ISO 834 1999) were performed to study the fire behaviour of the adhesives M1, P2, and P4 (Klippel et al. 2013). The following main conclusions can be drawn comparing the results obtained from the present small-scale tests and the large-scale fire tests:

- The PUR adhesives P2 and P4 reached about the same fire resistance as the MUF adhesive M1 although a lower tensile strength for $\mathrm{P} 2$ and $\mathrm{P} 4$ than for adhesive M1 was obtained at $220^{\circ} \mathrm{C}$ in the present small-scale tests.

- Taking into account the failure pattern of the fire tests, no significantdifference was observed between the adhesives P2, P4 and M1. Furthermore, the higher strength loss of some adhesives tested in small-scale tests at $220{ }^{\circ} \mathrm{C}$ does not necessarily lead to the same loss of strength in fire for structural size timber members, since the steep temperature gradient in the cross-section and defects like knots may be dominant as a failure reason - depending on the strength class (grading).

Large-scale fire tests are currently performed in accordance with the study by Klippel et al. (2013) with the

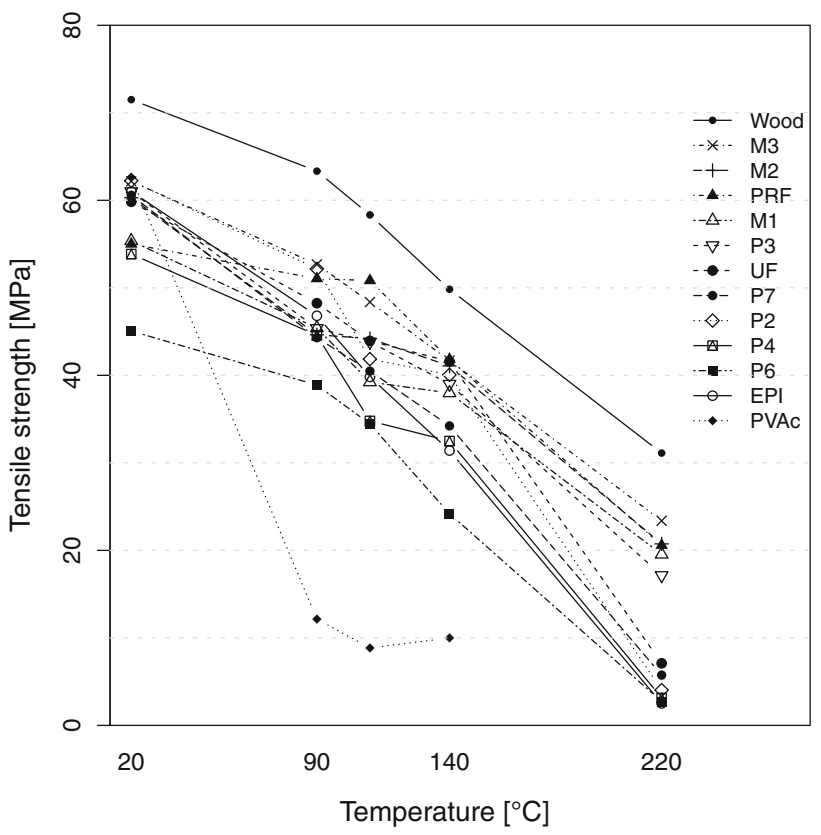

Fig. 9 Tensile strength as a function of temperature

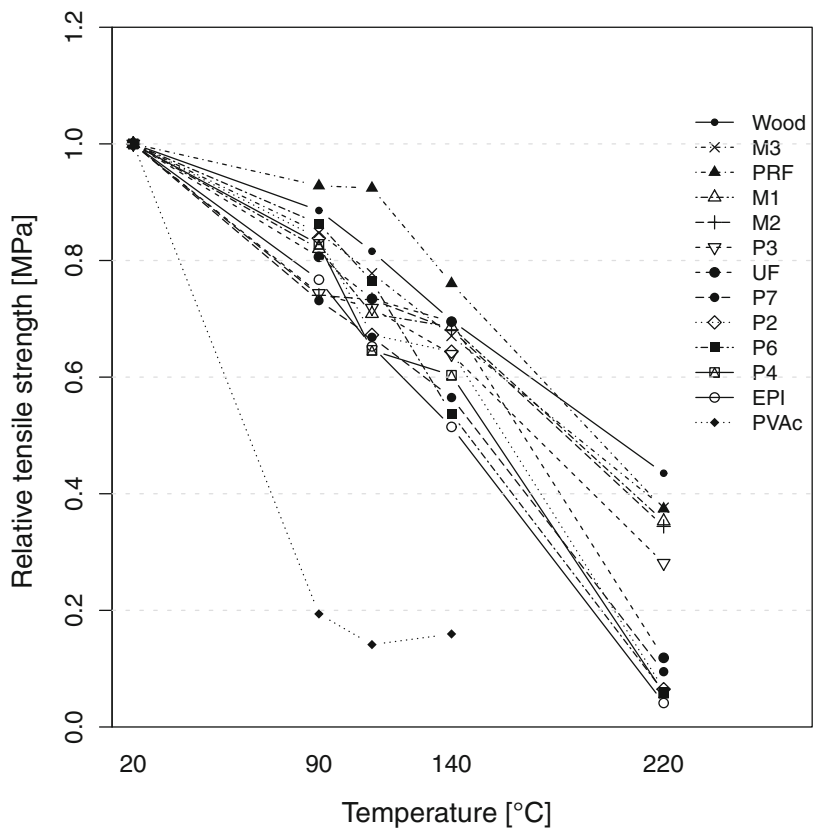

Fig. 10 Relative tensile strength as a function of temperature

remaining adhesives also tested in the present investigation. Subsequently, the results presented in this paper will be used to estimate the fire resistance obtained in the large-scale fire tests for all studied adhesives. The whole investigation will give a comprehensive background to establish an appropriate European testing method to test the fire performance of adhesives used in timber members such as glulam. 


\section{Conclusion}

The behaviour of finger-jointed small-scale timber members was studied with an extensive testing program at elevated temperatures. In total, 12 different adhesives were tested at temperatures between 20 and $220^{\circ} \mathrm{C}$. In the range between 20 and $140{ }^{\circ} \mathrm{C}$, the adhesive joints showed only moderate decrease in tensile strength with increasing temperature. Only for PVAc, a low tensile strength was obtained already at $90{ }^{\circ} \mathrm{C}$ due to its thermoplastic behaviour. Up to $220^{\circ} \mathrm{C}$, MUF and PRF adhesives showed mostly wood failure. Thus, it must be considered that in the case of these adhesives not the adhesive itself but rather the wood properties were tested.

For the PUR adhesives, a high variation in tensile strength was obtained, similar to the work by Clauß et al. (2011b). The PUR adhesive P3 reached analogue tensile strength to the MUF system for all temperatures tested. In addition, the specimens glued with P3 showed also at $220{ }^{\circ} \mathrm{C}$ a considerable amount of wood failure. For the other PUR adhesives, at $220^{\circ} \mathrm{C}$ no wood failure was obtained. In conclusion, the results of the work by Clauß et al. (2011b) were confirmed: The PUR adhesives exhibit a wide range of properties caused by their spectrum of assembly possibilities.

The development of appropriate small-scale testing methods should reflect the performance of the adhesives used in engineered wood products exposed to fire. Therefore, in the next step, the results obtained from the present investigation will be used to estimate the fire resistance obtained from large-scale fire tests, in which the same adhesive in the finger joints are studied. With these investigations, it should be possible to constitute a good foundation for the development of a European small-scale testing method to standardize the performance of adhesives in fire.

\section{References}

ASTM D3535-05 (2005) Standard test method for resistance to deformation under static loading for structural wood laminating adhesives used under exterior (wet use) exposure conditions. Annual Book of ASTM Standards, Philadelphia

ASTM D4688-99 (2005) Standard test method for evaluating structural adhesives for finger jointing lumber. Annual Book of ASTM Standards, vol. 15.06, Philadelphia

ASTM D7247-07 (2007) Standard test method for evaluating the shear strength of adhesive bonds in laminated wood products at elevated temperatures. ASTM, West Conshohocken, PA

ASTM E119-05a (2006) Standard test methods for fire tests of building construction and materials. ASTM, Philadelphia

CAN/ULC S101-07 (2007) Standard methods of fire endurance tests of building construction and materials. Underwriters' Laboratories of Canada, Scarborough, Canada
Clauß S, Dijkstra DJ, Gabriel J, Klausler O, Matner M, Meckel W, Niemz P (2011a) Influence of the chemical structure of PUR prepolymers on thermal stability. Int $\mathbf{J}$ Adhes Adhes 31(6):513-523

Clauß S, Joscak M, Niemz P (2011b) Thermal stability of glued wood joints measured by shear tests. Eur J Wood Wood Prod 69(1):101-111

Clauß S, Dijkstra DJ, Gabriel J, Karbach A, Matner M, Meckel W, Niemz P (2012) Influence of the filler material on the thermal stability of one-component moisture-curing polyurethane adhesives. J Appl Polym Sci 124(5):3641-3649

Colling F (1990) Tragfähigkeit von Biegeträgern aus Brettschichtholz in Abhängigkeit von den festigkeitsrelevanten Einflußgrößen. Dissertation der Fakultät für Bauingenieure- und Vermessungswesen der Universität Kalrsruhe

Craft ST, Desjardins R, Richardson LR (2008) Development of smallscale evaluation methods for wood adhesives at elevated temperatures. In: 10th world conference on timber engineering, Miyazaki, Japan 2008

CSA 0112.9-04 (2004) Evaluation of adhesives for structural wood products (exterior exposure). Canadian Standards Association, Mississauga, ON

EN 1194 (1999) Timber structures-glued laminated timberstrength classes and determination of characteristic values. European Norm EN 1194. CEN, Brussels, Belgium

EN 15416-2 (2013) Adhesives for load bearing timber structures other than phenolic and aminoplastic-test methods-part 2: static load test of multiple bondline specimens in compression shear

EN 15425 (2008) Adhesives-one component polyurethane for load bearing timber structures-classification and performance requirements. CEN/TC 193

EN 301 (2013) Adhesives-phenolic and aminoplastic-for loadbearing timber structures-classification and performance requirements

EN 302-1 (2013) Adhesives for load-bearing timber structures-test methods-part 1: determination of longitudinal tensile shear strength

EN 338 (2009) Structural timber-strength classes. Europäische Norm EN 338. CEN, Brussels, Belgium

Frangi A, Fontana M, Mischler A (2004) Shear behaviour of bond lines in glued laminated timber beams at high temperatures. Wood Sci Technol 38(2):119-126

Frangi A, Bertocchi M, Clauss S, Niemz P (2012) Mechanical behaviour of finger joints at elevated temperatures. Wood Sci Technol 46(5):793-812

George B, Simon C, Properzi M, Pizzi A, Elbez G (2003) Comparative creep characteristics of structural glulam wood adhesives. Holz Roh- Werkst 61(1):79-80

Gerhards C (1982) Effect of moisture and temperature on the mechanical properties of wood: an analysis of immediate effects. Wood Fiber 14(1):4-36

Glos P, Henrici D (1990) Festigkeit von Bauholz bei hohen Temperaturen, Abschlussbericht 87505

ISO 834 (1999) Fire-resistance tests-elements of building construction-part 1: general requirements ISO 834. International Organisation for Standardisation

Klippel M, Frangi A, Fontana M (2011) Influence of the Adhesive on the load-carrying capacity of glued laminated timber members in fire. In: 10th international symposium on fire safety science (IAFSS 2011) Fire safety science : proceedings of the tenth international symposium pp 1219-1232. doi:10.3801/IAFSS. FSS.10-1219

Klippel M, Frangi A, Hugi E (2013) Experimental analysis on the fire behavior of finger-jointed timber members. ASCE J Struct Eng (paper accepted for publication, online available). doi:10.1061/ (ASCE)ST.1943-541X.0000851 
König J, Norén J, Sterley M (2008) Effect of adhesives on finger joint performance in fire. In: Proceedings of 41th CIB-W18 meeting, St. Andrews, Canada. Paper CIB-W18/41-16-11

Mikkola E (1990) Charring of wood. VTT Research Notes, Espoo

Na B, Pizzi A, Delmotte L, Lu X (2005) One-component polyurethane adhesives for green wood gluing: structure and temperature-dependent creep. J Appl Polym Sci 96(4):1231-1243

Nielsen P, Olesen F (1982) Tensile strength of finger joints at elevated temperatures. vol Report No. 8205. Institute of Building Technology and Structural Engineering, Aalborg/Denmark

NTI (2009) Test procedure for approval of new adhesives for exposure condition A, B and C in the JAS system-face gluing of lamellae in conifer wood. Norsk Treteknisk Institutt, Norway
prEN 16254 (2013) Adhesives-emulsion polymerized isocyanate (EPI) for load-bearing timber structures-classification and performance requirements. CEN/TC 193

Richter K, Pizzi A, Despres A (2006) Thermal stability of structural one-component polyurethane adhesives for wood-structureproperty relationship. J Appl Polym Sci 102(6):5698-5707

Yeh B, Brooks R (2006) Evaluation of adhesive performance at elevated temperatures for engineered wood products. In: 9th world conference on timber engineering, Portland, USA 